\title{
MARKERS OF OXIDATIVE STRESS AFTER THREE DAYS OF NANOTIO, SUNSCREEN USE IN HUMANS: A PILOT STUDY
}

\author{
Daniela Pelclová', Tomáš Navrátil2, Zdenka Fenclová', Štěpánka Vlčková1 \\ ${ }^{1}$ Department of Occupational Medicine, First Faculty of Medicine, Charles University and General University Hospital, Prague, Czech Republic \\ 2J. Heyrovsky Institute of Physical Chemistry, Czech Academy of Sciences, Prague, Czech Republic
}

\section{SUMMARY}

Objective: Recent experimental studies point to a high reactivity of nanoparticles and the potential of sunscreens to penetrate the skin. We measured 20 markers of oxidative stress and inflammation to find out whether skin exposure to nanoTiO ${ }_{2}$ sunscreen may elevate the level of the markers in exhaled breath condensate (EBC) and urine of exposed subjects, as was suggested by our earlier study.

Methods: Six volunteers ( 3 males and 3 females), with a mean age of $48.0 \pm 6.7$ years, used commercial sunscreen for three days continuously. The first samples were collected before the test. The second samples were collected on day 4, before the sunscreen was washed off, and the third samples on day 11. The following biomarkers were measured: malondialdehyde, 4-hydroxy-trans-hexenal, 4-hydroxy-trans-nonenal, aldehydes C6-C12, 8-isoProstaglandin F2a, o-tyrosine, 3-chlorotyrosine, 3-nitrotyrosine, 8-hydroxy-2-deoxyguanosine, 8-hydroxyguanosine, 5-hydroxymethyl uracil, and leukotrienes B4, C4, D4, and E4, using liquid chromatography-electrospray ionisation-tandem mass spectrometry.

Results: In the urine, 4-hydroxy-trans-hexenal was significantly higher in post-exposure sample 2, and the same trend was seen in all urinary markers. In EBC, no difference was seen between the mean values of 20 post-test markers as compared with pre-test samples.

Conclusion: This study suggests potential side effects of the sunscreen - borderline elevation of markers of oxidative stress/inflammation which may relate to the absorption of the nanoTiO ${ }_{2}$, and the non-significant difference may be explained by the small number of subjects. The effect was not seen in $\mathrm{EBC}$, where nanoTiO ${ }_{2}$ was not found. A larger study is needed, as according to our previous study, the beneficial effect of the sunscreen to suppress oxidative stress caused by UV radiation may be questioned.

Key words: sunscreen, nanoTiO ${ }_{2}$, oxidative stress, inflammation, urine, exhaled breath condensate, nanoparticles absorption, nanotoxicology

Address for correspondence: D. Pelclová, Department of Occupational Medicine, First Faculty of Medicine, Charles University, Na Bojišti 1 , 12800 Prague 2, Czech Republic. E-mail: daniela@pelclova.cz

https://doi.org/10.21101/cejph.a6158

\section{INTRODUCTION}

Sunscreen use has been recommended as a cost-effective prevention of skin cancer. However, experimental studies have reported potentially unfavourable effects of sunscreens, and there are concerns regarding the safety of nanoTiO ${ }_{2}$, because it can extend the duration of sunbathing and increase the risk of skin malignancies $(1,2)$. Other studies point to a high reactivity of nanoparticles and their potential to produce reactive oxygen species (ROS) (3-6), alter the skin structure (7), and/or penetrate the skin $(8-10)$, similarly to organic components $(11,12)$. For particles $4-20 \mathrm{~nm}$, the penetration happens mostly through the hair follicles, and particles smaller than $4 \mathrm{~nm}$ may pass based on the skin physiology and diffusion theory $(13,14)$.

One of the most frequently used nanoparticles in inorganic sunscreens is $\mathrm{TiO}_{2}$, which is able to reflect, scatter, and absorb UV radiation (15); however, production of ROS capable of altering DNA has also been described $(16,17)$. In 2010, the International Agency for Research on Cancer reclassified $\mathrm{TiO}_{2}$ as a group $2 \mathrm{~B}$ carcinogen, i.e., possibly carcinogenic to humans (18). Additionally, in experimental studies, nano $\mathrm{TiO}_{2}$ toxicity was higher than that of bulk $\mathrm{TiO}_{2}$ because of the higher reactivity of the nanoparticles due to a highly active surface area (hundreds $\mathrm{m}^{2} / \mathrm{g}$ ). Three main mechanisms have been suggested for nanoTiO 2 : ROS production following the induction of electron-hole pairs; damage of the cell membranes due to lipid peroxidation by the attachment of nanoparticles to cells via electrostatic forces as a result of their large specific surface area; and $\mathrm{TiO}_{2}$ nanoparticle attachment to intracellular organelles and macromolecules following cell membrane damage (15).

Our last study proved the skin absorption of nanoTiO $\mathrm{TiO}_{2}$ by both Ti measured by inductively coupled plasma mass spectrometry and nano $\mathrm{TiO}_{2}$ particles detected by transmission and scanning electron microscopy (TEM and SEM) in the plasma and urine in all sunscreen users. Importantly, nanoTiO particles have not been found in exhaled breath condensate (EBC) (19) - i.e. liquid, collected during tidal breathing, presumably originating from the airway lining fluid in the form of aerosolised particles generated during the re-opening of distal airways. This excludes entering by inhalation route and documents that nano $\mathrm{TiO}_{2}$ can penetrate beyond the outer layers of stratum corneum to viable cells and reach the general circulation. The amounts, however, were very small (mean $8.9 \pm 2.8 \mathrm{ng} / \mathrm{ml}$ and $6.7 \pm 1.6$ in plasma and urine, respectively). In that study, we tested the efficiency of nanoTiO 
sunscreen to prevent systemic oxidative stress/inflammation caused by ultraviolet (UV) radiation using biomarkers in subjects' plasma, urine, and EBC. Indeed, UV exposure alone in the commercial solarium significantly increased all biomarkers in the plasma, urine, and EBC of the volunteers, but rather surprisingly, the sunscreens applied before UV exposure did not supress the significant elevation of any oxidative stress/inflammatory marker due to UV radiation.

In the urine, leukotriene C4 (LTC4) was significantly higher on day $4(p<0.05)$. A few markers were elevated in the post-exposure EBC samples $(p<0.05)$, but there was not a clear trend. Among them, 3-chlorotyrosine (3-ClTyr) was found on day 4, and 8-isoProstaglandin F2 $\alpha$ (8-isoprostane), LTC4, and LTD4 on day 11.

In humans, several markers of oxidation have been used to evaluate oxidative stress in biological fluids, especially blood and urine. In proteins, 3-ClTyr is a specific molecular marker of the production of chlorinating oxidants in leukocytes; 3-nitrotyrosine (3-NOTyr) is a marker for nitration stress, which may lead to functional relationship with the neutrophilic inflammation; and $o$-tyrosine (o-Tyr) is an amino-acid oxidation biomarker (20). They have also been found in the EBC or sputum of patients with interstitial lung diseases (21).

For the lipid oxidation, 8-isoprostane represents an in vivo marker produced by free-radical lipid peroxidation of arachidonic acid. Oxidative modification of lipids occurs in vivo during ageing and in several disease conditions (20). Lipid peroxides are unstable indicators of oxidative stress in cells that form more reactive compounds, such as aldehydes C6-C12, malondialdehyde (MDA), 4-hydroxy-trans-hexenal (HHE), and 4-hydroxy-trans-nonenal (HNE), forming covalent adducts with biomolecules including DNA and proteins, and thus are regarded as genotoxic and cytotoxic (22). Oxidative damage to nucleic acids may be measured using 8-hydroxy-2-deoxyguanosine (8-OHdG) and 8-hydroxyguanosine (8-OHG) formed by oxidation of guanine from DNA and 5-hydroxymethyl uracil (5-OHMeU) from RNA (23).

LTs are low-molecular inflammatory biomarkers. They are primarily produced by leukocytes from the arachidonic acid and are known to have powerful effects over short distances within the body (20). They play an active role in inflammatory responses and initiate tissue repair. They are involved in the pathogenesis of different respiratory disorders, especially chronic obstructive pulmonary disease (LTB4), asthma (24), and fibrosis (25).

The aim of this study was to replicate sunscreen exposure (19) under the same conditions (identical sunscreen type, length of sunscreen exposure, and length of the study with $5 / 6$ of the same subjects) with three collected samples using non-invasive collection methods (i.e., EBC and urine) to confirm or exclude the effect.

\section{MATERIALS AND METHODS}

Six volunteers ( 3 males and 3 females), all non-smokers with a mean age of $48.0 \pm 6.7$ years, used commercial sunscreen containing $\mathrm{TiO}_{2}$ nanoparticles for three days. Five out of the six subjects participated in the earlier sunscreen study. The study was approved by the Ethics Committee of Charles University according to the Helsinki criteria. All participants were informed of the study aim and signed an informed consent form prior to the beginning of the study, and they filled in a standardised question- naire that included the personal and occupational history, acute and chronic symptoms, and medications. Their urine and EBC were subsequently collected.

The first samples of EBC and urine were taken at the beginning of the test before the sunscreen application. The sunscreen was applied to approximately $80 \%$ of the body surface twice daily and was not washed off. The volunteers wore white shirts and white trousers that remained unchanged until day 4. After the second samples were collected, the used sunscreen was thoroughly washed off. The third samples were collected on day 11 (i.e., one week after the end of sunscreen exposure).

The sunscreen type was identical to the sunscreen used in the published study (19). It had a skin protection factor (SPF) of 50 . The total content of the tube was $150 \mathrm{~g}$. The recommended dosage was $2 \mathrm{mg} / \mathrm{cm}^{2}$ skin - i.e., approximately 6 teaspoons (30 g)/adult - to be re-applied to maintain a sufficient level typically twice a day.

EBC samples were collected using an Ecoscreen Turbo (DECCS, Jaeger, Hochberg, Germany). All subjects wore a nose clip to avoid nasal contamination and breathed tidally for approximately 15 min through a mouthpiece connected to the condenser $\left(-20{ }^{\circ} \mathrm{C}\right)$, as described in our previous study (19).

An identical panel of markers of oxidative stress/inflammation was analysed in urine and EBC. These markers included MDA, HHE, HNE, aldehydes C6-C12, 8-isoprostane, o-Tyr, 3-ClTyr, 3-NOTyr, 8-OHdG, 8-OHG, 5-OHMeU, and LTs. The analysis was performed following solid-phase extraction (SPE) in the same laboratory using high-performance liquid chromatography-electrospray ionisation-tandem mass spectrometry (HPLC-ESI-MS/MS), using a quaternary pump, Accela 600, and Accela autosampler coupled to a triple quadrupole mass spectrometer TSQ Vantage equipped with heated electrospray ionisation (HESI) (Thermo Fisher Scientific).

Basic descriptive statistics were computed and subsequently tested for normality using the Kolmogorov-Smirnov test. For comparison of frequency counts of demographic categorical variables, Fischer's exact test was used. Differences in interval variables were tested using the Mann-Whitney U test. A paired sample t-test was used to compare pre-exposure and post-exposure values of the markers. Statistical significance was set at $p<0.05$. Statistical analyses were conducted using MS Excel 365, QC Expert 3.3, and SPSS version 22.0.

\section{RESULTS}

Two subjects reported allergic rhinitis without treatment, and one woman was being treated with thyroxin for hypothyroidism and with local corticosteroids for bronchial asthma; these subjects also participated in the previous study (19). No subject had symptoms of an acute viral disease, chronic bronchitis, or dyspnoea. The average total cream consumption was $131.3 \pm 9.9 \mathrm{~g}$, which was similar to the first study. The amylase concentration in all samples was less than $0.01 \%$ of the alpha-amylase concentration in saliva.

Mean levels of oxidative stress and inflammatory markers in the pre-exposure urine and post-exposure on day 4 (sample 2), when the sunscreen was removed, and one week later (day 11, sample 3) are shown in Figure 1 and Figure 2. Only one marker, 


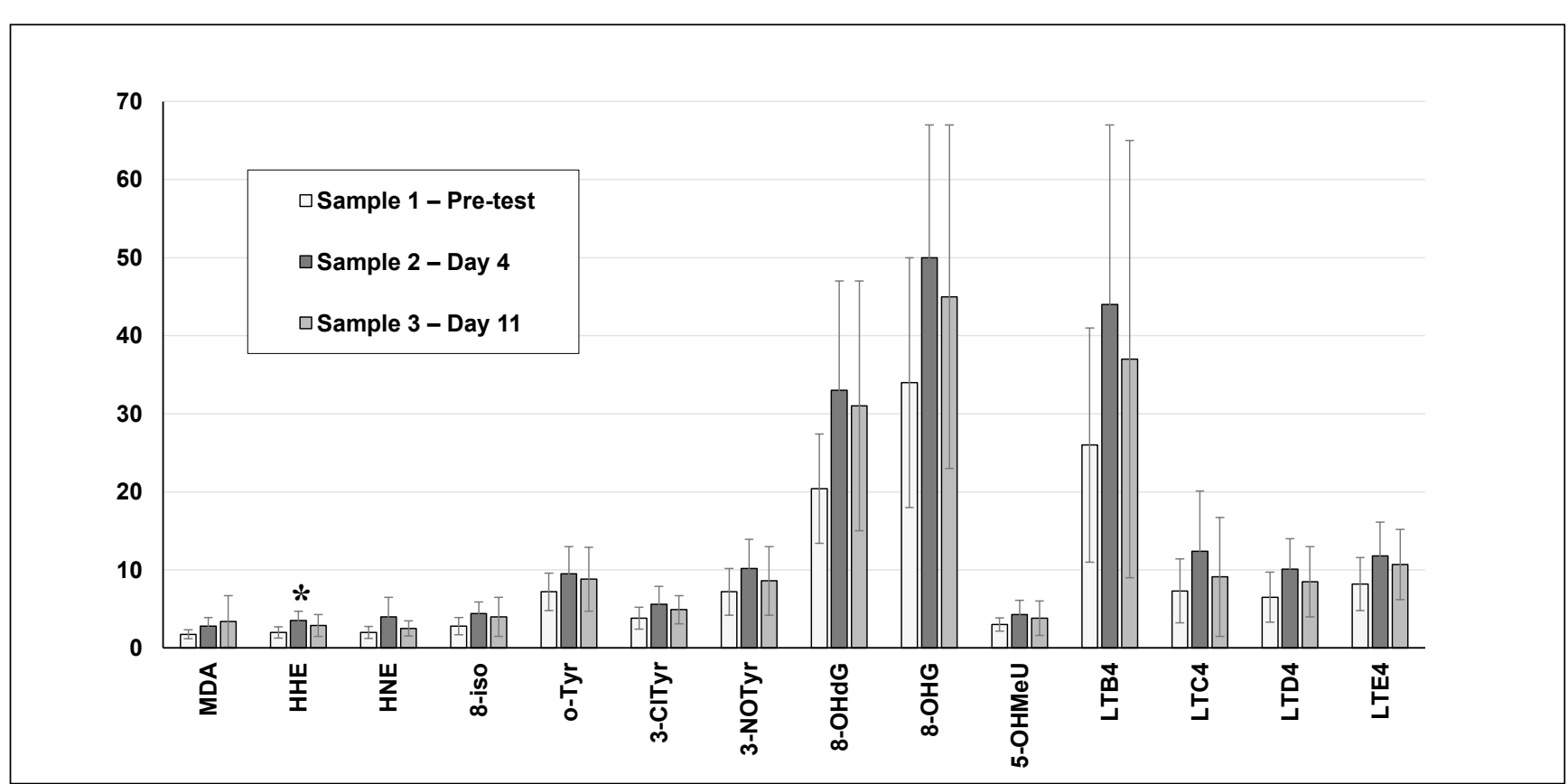

Fig. 1. Markers of oxidative stress and inflammatory markers in urine pre-exposure (sample 1) and after sunscreen exposure (samples 2-3), mean \pm confidence intervals

MDA - malondialdehyde; HHE - 4-hydroxy-trans-hexenal; HNE - 4-hydroxy-trans-nonenal (all ng/mmol creatinine); 8-iso - 8-isoProstaglandin F2a; o-Tyr - o-tyrosine; 3-CITyr - 3-chlorotyrosine; 3-NOTyr - 3-nitrotyrosine; 8-OHdG - 8-hydroxy-2-deoxyguanosine; 8-OHG - 8-hydroxyguanosine; 5-OHMeU - 5-hydroxymethyl uracil; leukotrienes (LT) LTB4, LTC4, LTD4, LTE4 (all pg/mmol creatinine). ${ }^{*} \mathrm{p}=0.027$

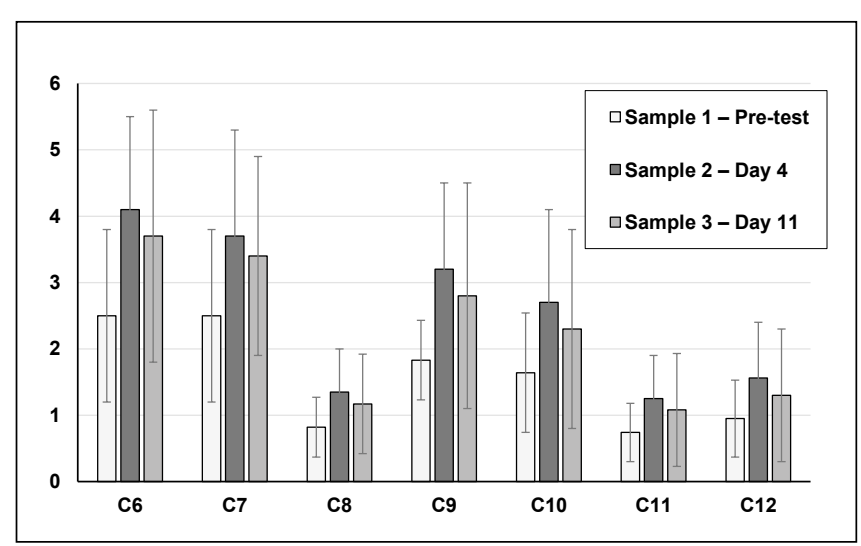

Fig. 2. Markers of oxidative stress - aldehydes C6-C12 in urine ( $\mathrm{ng} / \mathrm{mmol}$ creatinine), mean \pm confidence intervals

HHE, was significantly increased in sample $2(p=0.027)$ in the urine, and a trend in the elevation of all post-exposure markers in sample 2 could be noticed in both figures in comparison with pre-exposure levels. Also, the absolute values of all markers in sample 3 were higher than in sample 1, although the difference was not significant. No statistically significant elevation of any marker of oxidative stress and/or inflammation could be seen in EBC, as presented in Figure 3 and Figure 4.

\section{DISCUSSION}

A large body of in vivo and in vitro nanotoxicology studies has shown that nanoparticles induce intracellular ROS and pro-inflammatory mediators. Much less data are available concerning studies on human subjects using mineral nano sunscreens.

It was shown that the skin absorption of nano $\mathrm{TiO}_{2}$ already occurs after the first 6 hours of exposure, although in a small quantity (19). This agrees with the histological proof of nanoTiO 2 particles in the viable cells of both the epidermis and dermis in the study by Tan et al. (26). This may explain the borderline elevation of the markers of oxidative stress and inflammation in the biological samples collected in this study with the limited number of volunteers using nanoTiO sunscreen. Here, only one significantly elevated biomarker in the urine, HHE $(p=0.027)$, was found in sample 2 after three days of exposure, and although it decreased on day 11, its absolute level was still (from the statistical point of view nonsignificantly, $\mathrm{p}=0.13$ ) higher than in sample 1 . All remaining urine markers showed the same trend.

Differently, no EBC markers were elevated in this study, and no positive trend was noted. Some elevations in our previous study concerned especially LTs, inflammation markers that may reflect subclinical inflammation in the respiratory system, as they are involved in the response to injury, infection, or allergy (27-29). Therefore, markers in EBC usually reflect occupational exposures of workers to nanomaterials by inhalation (30-34), including office employees exposed to nanoTiO 2 (35). Due to the potential of sunscreen in the spray form to be absorbed by inhalation, such products have been classified as potentially hazardous and are no longer allowed (36). Differently, elevated markers of oxidative stress in the plasma and urine were associated with ageing, metabolic diseases $(20,37)$, or systemic intoxications (38). Under the conditions of skin sunscreen exposure, the inhalational way of exposure was excluded in our last study (19), which did not find nanoTiO 2 particles in $\mathrm{EBC}$, 


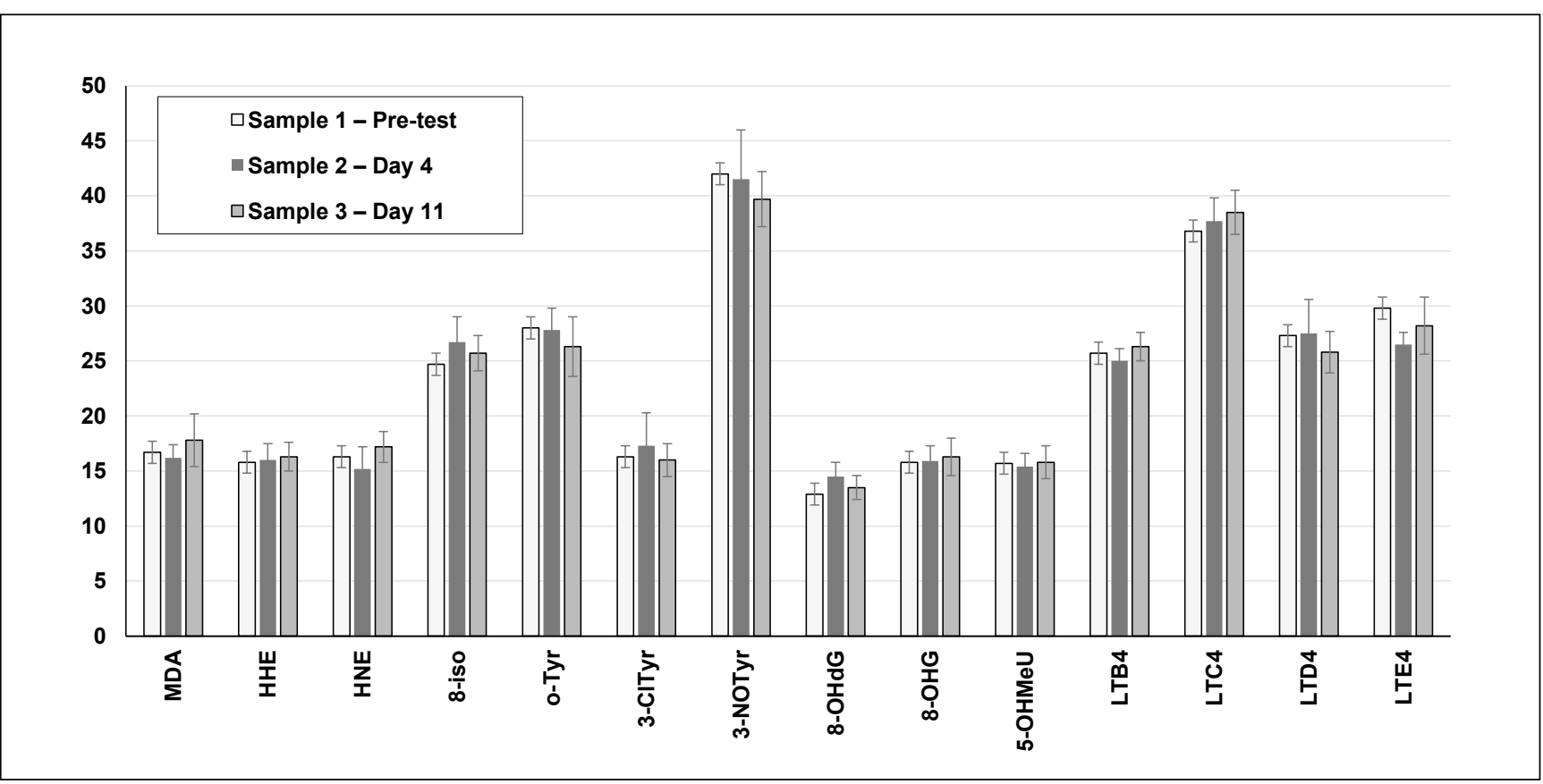

Fig. 3. Markers of oxidative stress and inflammatory markers in exhaled breath condensate pre-exposure (sample 1) and after sunscreen exposure (samples 2-3), mean \pm confidence intervals

MDA - malondialdehyde; HHE - 4-hydroxy-trans-hexenal; HNE - 4-hydroxy-trans-nonenal (all ng/ml); 8-iso - 8-isoProstaglandin F2 $\alpha$; o-Tyr - o-tyrosine; 3-CITyr 3-chlorotyrosine; 3-NOTyr - 3-nitrotyrosine; 8-OHdG - 8-hydroxy-2-deoxyguanosine; 8-OHG - 8-hydroxyguanosine; 5-OHMeU - 5-hydroxymethyl uracil; leukotrienes (LT) LTB4, LTC4, LTD4, LTE4 (all pg/ml)

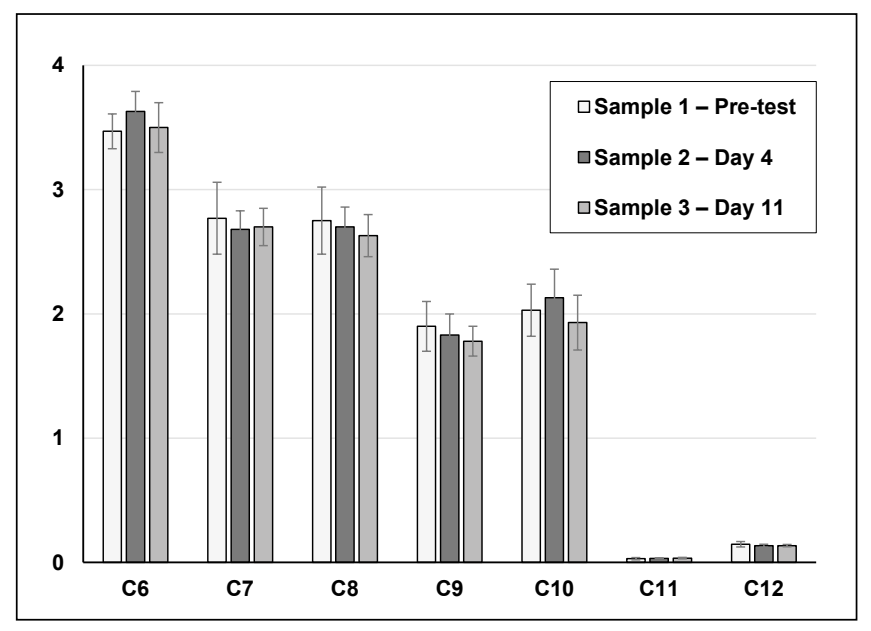

Fig. 4. Markers of oxidative stress - aldehydes C6-C12 in exhaled breath condensate ( $\mathrm{ng} / \mathrm{ml})$, mean \pm confidence intervals

but they were present in nanoTiO 2 workers at both post-shift and pre-shift (39).

Potential contamination between skin-hands-mouth cannot be completely excluded, however, the absorption from the gastrointestinal tract is very limited (40), therefore, we suppose it could bring unmeasurable plasma and urine levels. In addition, there is no explanation why it would be more pronounced in females. In addition, it would be expected, that the nanoparticles, the origin of which would be the skin-hands-mouth contamination, would keep the original size, approximately $43 \mathrm{~nm}$, as oral absorption enables absorption of larger particles, with average much higher than in our plasma and urine samples. In a study in human volunteers, their oral exposure of 100 -mg dose of $\mathrm{TiO}_{2}$ particles with diameter $50-260 \mathrm{~nm}$ led to their appearance in the blood (41).

The main limitation of this study is the low number of exposed subjects. Based on these results, both the safety and effect of nanoTiO $\mathrm{TiO}_{2}$ may be questioned and should be further studied. It was shown in our previous study that they only reduced skin redness induced by UV radiation in our previous test; however, they did not lower systemic oxidative stress caused by UV radiation.

\section{CONCLUSIONS}

Since absorption of nano $\mathrm{TiO}_{2}$ from sunscreen occurs, systemic oxidative stress and inflammation cannot be excluded. In this study, a statistically significant increase of HHE in post-exposure sample 2 was detected. The same trend, although statistically non-significant, was seen in all remaining 19 urine markers. The inhalation route of entering the body under this condition was excluded, which agrees with the normal EBC finding in this study. A larger study is urgently needed to prove both the safety and usefulness of nanoTiO ${ }_{2}$ sunscreens.

\section{Acknowledgements}

The authors wish to thank all volunteers who took part in this study. The study was supported by grant Progres Q25 and Q29 of the Charles University, and GACR 18-02079S.

\section{Conflict of Interests}

None declared 


\section{REFERENCES}

1. Dréno B, Alexis A, Chuberre B, Marinovich M. Safety of titanium dioxide nanoparticles in cosmetics. J Eur Acad Dermatol Venereol. 2019;33 Suppl 7:34-46

2. Solaiman SM, Algie J, Bakand S, Sluyter R, Sencadas V, Lerch M, et al. Nano-sunscreens - a double-edged sword in protecting consumers from harm: viewing Australian regulatory policies through the lenses of the European Union. Crit Rev Toxicol. 2019;49(2):122-39.

3. Rossnerova A, Pelclova D, Zdimal V, Rossner P Jr, Elzeinova F, Vrbova $\mathrm{K}$, et al. Micronuclei levels in nanocomposites production workers: interpretation of results from two years of monitoring. In: NANOCON 2018: Proceedings of the 10th Anniversary International Conference on Nanomaterials - Research \& Application; 2018 Oct 17-19; Brno, Czech Republic, EU. Ostrava: TANGER; 2019. p. 554-9.

4. Rossnerova A, Pelclova D, Zdimal V, Rossner Jr P, Elzeinova F, Vrbova $\mathrm{K}$, et al. The repeated cytogenetic analysis of subjects occupationally exposed to nanoparticles: a pilot study. Mutagenesis. 2019;34(3):253-6.

5. Hubacek JA, Pelclova D, Dlouha D, Mikuska P, Dvorackova S, Vlckova $\mathrm{S}$, et al. Leukocyte telomere length is not affected by long-term occupational exposure to nano metal oxides. Ind Health. 2019;57(6):741-4.

6. Novotna B, Pelclova D, Rossnerova A, Zdimal V, Ondracek J, Lischkova $\mathrm{L}$, et al. The genotoxic effects in the leukocytes of workers handling nanocomposite materials. Mutagenesis. 2020 Jul 23;geaa016. doi: 10.1093/mutage/geaa016. Online ahead of print.

7. Shi H, Magaye R, Castranova V, Zhao J. Titanium dioxide nanoparticles: a review of current toxicological data. Part Fibre Toxicol. 2013;10:15. doi: 10.1186/1743-8977-10-15.

8. Gulson B, McCall M, Korsch M, Gomez L, Casey P, Oytam Y, et al. Small amounts of zinc from zinc oxide particles in sunscreens applied outdoors are absorbed through human skin. Toxicol Sci. 2010;118(1):140-9.

9. Larese Filon F, Crosera M, Mauro M, Baracchini E, Bovenzi M, Montini T, et al. Palladium nanoparticles exposure: evaluation of permeation through damaged and intact human skin. Environ Pollut 2016;214:497-503.

10. Turci F, Peira E, Corazzari I, Fenoglio I, Trotta M, Fubini B. Crystalline phase modulates the potency of nanometric $\mathrm{TiO}_{2}$ to adhere to and perturb the stratum corneum of porcine skin under indoor light. Chem Res Toxicol. 2013;26(10):1579-90.

11. Matta MK, Florian J, Zusterzeel R, Pilli NR, Patel V, Volpe DA, et al. Effect of sunscreen application on plasma concentration of sunscreen active ingredients: a randomized clinical trial. JAMA. 2020;323(3):256-67.

12. Adamson AS, Shinkai K. Systemic Absorption of sunscreen: balancing benefits with unknown harms. JAMA. 2020;323(3):223-4.

13. Larese Filon F, Mauro M, Adami G, Bovenzi M, Crosera M. Nanoparticles skin absorption: new aspects for a safety profile evaluation. Regul Toxicol Pharmacol. 2015;72(2):310-22.

14. Larese Filon F, Bello D, Cherrie JW, Sleeuwenhoek A, Spaan S, Brouwer DH. Occupational dermal exposure to nanoparticles and nano-enabled products: part I-factors affecting skin absorption. Int J Hyg Environ Health. 2016;219(6):536-44.

15. Hou J, Wang L, Wang C, Zhang S, Liu H, Li S, et al. Toxicity and mechanisms of action of titanium dioxide nanoparticles in living organisms. J Environ Sci. 2019;75:40-53.

16. Tran DT, Salmon R. Potential photocarcinogenic effects of nanoparticle sunscreens. Australas J Dermatol. 2011;52(1):1-6.

17. Trouiller B, Reliene R, Westbrook A, Solaimani P, Schiestl RH. Titanium dioxide nanoparticles induce DNA damage and genetic instability in vivo in mice. Cancer Res. 2009;69(22):8784-9.

18. IARC Working Group on the Evaluation of Carcinogenic Risks to Humans. Carbon black, titanium dioxide, and talc. IARC Monogr Eval Carcinog Risks Hum. 2010;93:1-413.

19. Pelclova D, Navratil T, Kacerova T, Zamostna B, Fenclova Z, Vlckova $\mathrm{S}$, et al. NanoTiO ${ }_{2}$ sunscreen does not prevent systemic oxidative stress caused by UV radiation and a minor amount of nano $\mathrm{TiO}_{2}$ is absorbed in humans. Nanomaterials (Basel). 2019;9(6):888. doi: 10.3390/ nano9060888.

20. Syslova K, Böhmova A, Mikoska M, Kuzma M, Pelclova D, Kacer P. Multimarker screening of oxidative stress in aging. Oxid Med Cell Longev. 2014;2014:562860. doi: 10.1155/2014/562860.

21. Antus, B. Oxidative stress markers in sputum. Oxid Med Cell Longev. 2016;2016:2930434. doi: 10.1155/2016/2930434
22. Møller P, Danielsen PH, Karottki DG, Jantzen K, Roursgaard M, $\mathrm{K}$ lingberg $\mathrm{H}$, et al. Oxidative stress and inflammation generated DNA damage by exposure to air pollution particles. Mutat Res Rev Mutat Res. 2014;762:133-66.

23. Manke A, Wang L, Rojanasakul Y. Mechanisms of nanoparticle-induced oxidative stress and toxicity. Biomed Res Int. 2013;2013:942916. doi: 10.1155/2013/942916.

24. Klusackova P, Lebedova J, Kacer P, Kuzma M, Brabec M, Pelclova D, et al. Leukotrienes and 8-isoprostane in exhaled breath condensate in bronchoprovocation tests with occupational allergens. Prostaglandins Leukot Essent Fatty Acids. 2008;78(4-5):281-92.

25. Pelclová D, Fenclová Z, Vlcková S, Lebedová J, Syslová K, Pecha $\mathrm{O}$, et al. Leukotrienes B4, C4, D4 and E4 in the exhaled breath condensate (EBC), blood and urine in patients with pneumoconiosis. Ind Health. 2012;50(4):299-306.

26. Tan MH, Commens CA, Burnett L, Snitch PJ. A pilot study on the percutaneous absorption of microfine titanium dioxide from sunscreens. Australas J Dermatol. 1996;37(4):185-7.

27. Peters-Golden M. Expanding roles for leukotrienes in airway inflammation. Curr Allergy Asthma Rep. 2008;8(4):367-73.

28. Elajami TK, Colas RA, Dalli J, Chiang N, Serhan CN, Welty FK. Specialized proresolving lipid mediators in patients with coronary artery disease and their potential for clot remodelling. FASEB J. 2016;30(8):2792-801.

29. Duvall MG, Bruggemann TR, Levy BD. Bronchoprotective mechanisms for specialized pro-resolving mediators in the resolution of lung inflammation. Mol Aspects Med. 2017;58:44-56.

30. Pelclova D, Zdimal V, Schwarz J, Dvorackova S, Komarc M, Ondracek $\mathrm{J}$, et al. Markers of oxidative stress in the exhaled breath condensate of workers handling nanocomposites. Nanomaterials (Basel). 2018;8(8):611. doi: 10.3390/nano8080611.

31. Pelclova D, Zdimal V, Komarc M, Vlckova S, Fenclova Z, Ondracek J, et al. Deep airway inflammation and respiratory disorders in nanocomposite workers. Nanomaterials (Basel). 2018;8(9):731. doi: 10.3390/ nano8090731.

32. Pelclova D, Zdimal V, Kacer P, Fenclova Z, Vlckova S, Komarc M, et al. Leukotrienes in exhaled breath condensate and fractional exhaled nitric oxide in workers exposed to $\mathrm{TiO}_{2}$ nanoparticles. J Breath Res. 2016;10(3):036004. doi: 10.1088/1752-7155/10/3/036004.

33. Pelclova D, Zdimal V, Fenclova Z, Vlckova S, Turci F, Corazzari I, et al. Markers of oxidative damage of nucleic acids and proteins among workers exposed to $\mathrm{TiO}_{2}$ (nano) particles. Occup Environ Med. 2016;73(2):110-8.

34. Pelclova D, Fenclova Z, Kacer P, Kuzma M, Navratil T, Lebedova J. Increased 8-isoprostane, a marker of oxidative stress in exhaled breath condensate in subjects with asbestos exposure. Ind Health. 2008;46(5):484-9.

35. Pelclova D, Zdimal V, Kacer P, Komarc M, Fenclova Z, Vlckova S, et al. Markers of lipid oxidative damage among office workers exposed intermittently to air pollutants including nanoTiO 2 particles. Rev Environ Health. 2017;32(1-2):193-200.

36. Scientific Committee on Consumer Safety. Opinion on Titanium Dioxide (nano form) as UV-Filter in sprays - SCCS/1583/17 [Internet]. Brussels: European Commission; 2018 [cited 2020 Feb 11]. Available from: https://ec.europa.eu/health/sites/health/files/scientific committees/ consumer_safety/docs/sccs_o_206.pdf.

37. Pelcl T, Skrha J Jr, Soupal J, Flekac M, Kacer P, Skrha J, et al. Lipid peroxidation and impaired vascular function in patients with type 1 diabetes mellitus. Monatsh Chem. 2019;150:525-9.

38. Pelclova D, Navratil T, Vlckova S, Fenclova Z, Pelcl T, Kacerova T, et al. Exhaled breath condensate biomarkers reflect systemic changes in patients with chronic dioxin intoxication. Monatsh Chem. 2018;149:579-86.

39. Pelclova D, Barosova H, Kukutschova J, Zdimal V, Navratil T, Fenclova $Z$, et al. Raman microspectroscopy of exhaled breath condensate and urine in workers exposed to fine and nano $\mathrm{TiO}_{2}$ particles: a crosssectional study. J Breath Res. 2015;9(3):036008. doi: 10.1088/17527155/9/3/036008.

40. Winkler HC, Notter T, Meyer U, Naegeli H. Critical review of the safety assessment of titanium dioxide additives in food. J Nanobiotechnology. 2018;16(1):51. doi: 10.1186/s12951-018-0376-8.

41. Pele LC, Thoree V, Bruggraber SF, Koller D, Thompson RP, Lomer MC, et al. Pharmaceutical/food grade titanium dioxide particles are absorbed into the bloodstream of human volunteers. Part Fibre Toxicol. 2015,12:26. doi: 10.1186/s12989-015-0101-9. 